\title{
Myocardial Carbohydrate, Ketone, and Fatty Acid Uptake in Conscious Lambs with Aortopulmonary Shunts ${ }^{1}$
}

\author{
J. W. C. GRATAMA, M. DALINGHAUS, J. J. MEUZELAAR, A. M. GERDING, J. H. KOERS, \\ F. A. J. MUSKIET, AND J. R. G. KUIPERS \\ Departments of Pediatrics, Thoracic Surgery, and Central Laboratory for Clinical Chemistry, University of \\ Groningen, Groningen, The Netherlands
}

\begin{abstract}
A left to right shunt increases myocardial work and is often accompanied by increased catecholamine levels. Because both increased myocardial work and increased catecholamine levels may induce increased fatty acid utilization, which could increase resting myocardial oxygen consumption and therefore unfavorably affect coronary reserve, we studied myocardial uptake of glucose, pyruvate, lactate, $\beta$-OH-butyrate, acetoacetate, FFA, and triglycerides in 12 7-wk-old lambs with aortopulmonary left to right shunts $(58 \pm 2 \%$ of left ventricular output, mean \pm SEM) and in 10 control lambs 2 wk after surgery. Despite the shunt, systemic blood flow in the shunt lambs was maintained at the same level as in the control lambs. This was accomplished by an increased heart rate and stroke volume. Furthermore, the shunt was accompanied by an increased myocardial oxygen consumption in the shunt lambs $\left(834 \pm 70\right.$ versus $528 \pm 43 \mu \mathrm{mol} \mathrm{O} \mathrm{O}_{2} \cdot \mathrm{min}^{-1}$. $\left.100 \mathrm{~g}^{-1} ; p<0.05\right)$. There were no significant differences in arterial substrate concentrations between the two groups. The same was true for arteriovenous differences across the myocardium, with the exception of lactate, which was substantially higher in shunt than in control lambs (72 \pm 25 versus $18 \pm 23 \mu \mathrm{mol} / \mathrm{L} ; p<0.05$ ). As a consequence, myocardial lactate uptake in the shunt lambs was increased 15 -fold $\left(18 \pm 6\right.$ versus $1 \pm 2 \mu \mathrm{mol} \cdot \mathrm{min}^{-1} \cdot 100 \mathrm{~g}^{-1} ; p<$ 0.02 ), whereas uptake of the other substrates merely paralleled the increased myocardial blood flow. Our data demonstrate that myocardial substrate uptake is not substantially different between shunt and control lambs, with the exception of lactate, of which the extraction is $\mathbf{1 0}$-fold higher than in control lambs. We speculate that the increased myocardial lactate utilization may reflect an increase of lactate and pyruvate dehydrogenase activities. (Pediatr Res 32: 27-32, 1992)
\end{abstract}

\section{Abbreviations}

LDH, lactate dehydrogenase

PDH, pyruvate dehydrogenase

OER, oxygen extraction ratio
Received September 6, 1991; accepted February 17, 1992.

Correspondence and reprint requests: Jaap R. G. Kuipers, M.D., Department of Pediatrics, Division of Pediatric Cardiology, University Hospital, Oostersingel 59, $9713 \mathrm{EZ}$ Groningen, The Netherlands.

Supported by a grant from the Netherlands Heart Foundation (85.089).

' Presented in part at the Annual Scientific Session of the Society for Pediatric Research, May 1989, Washington, DC.
A left to right shunt through a ventricular septal defect or ductus arteriosus imposes an increased work load on the heart because of its effect on left ventricular wall stress, external work, contractility, and heart rate (1-3). This effect is accompanied by an increased myocardial oxygen consumption (3), which reflects increased oxidation of substrates to meet the increased ATP demand (4). Often, an increased work load leads not only to increased substrate uptake, but also to a change in the pattern of myocardial substrate utilization (5), as has been shown in hearts with increased afterload (6), contractility (7), and thyroxineinduced volume load $(8,9)$ and during exercise $(5,10-12)$. Furthermore, catecholamines are often increased in the presence of a substantial left to right shunt (13), and they are also known to affect myocardial metabolism $(14,15)$. Through their effect on myocardial performance, catecholamines stimulate glucose and fatty acid utilization by the myocardium, and, through activation of lipoprotein lipase, they enhance fatty acid utilization $(5,14-16)$.

These considerations suggest that a left to right shunt could lead to a change in myocardial substrate metabolism. A shift toward increased fatty acid uptake could increase myocardial oxygen consumption because of the low phosphorylation/oxidation ratio, i.e. mol of ADP phosphorylated per mol $\mathrm{O}$ consumed $(4,17,18)$. This would create an unfavorable situation because myocardial oxygen consumption is already high because of the increased work load of the heart. An added increase in oxygen demand would have to be met by an increased myocardial blood flow and would thus result in a decreased coronary blood flow reserve. In addition to the effects on myocardial oxygen consumption mentioned above, adverse effects of enhanced fatty acid uptake on myocardial performance have also been reported in isolated hearts (19-22). If, instead of an increase in fatty acid uptake, a shift toward increased glucose or lactate uptake would occur, as occurs during the increased myocardial work accompanying exercise $(10-12,17)$, this would probably not be unfavorable. This is supported by the finding that enhanced glucose utilization decreases myocardial oxygen consumption (23). Insight into the metabolism of hearts with an aortopulmonary left to right shunt could add to the understanding of the pathophysiology of subjects with such a shunt.

Accordingly, the objective of this study was to analyze myocardial substrate uptake in lambs with an aortopulmonary left to right shunt by measuring the myocardial uptake of glucose, pyruvate, lactate, $\beta$-OH-butyrate, acetoacetate, FFA, and triglycerides.

\section{MATERIALS AND METHODS}

We studied 22 7-wk-old lambs of mixed breed with documented dates of birth. They were divided into two groups: 12 lambs with an aortopulmonary left to right shunt and 10 lambs 
without a shunt, which served as controls. Until the day of study, each lamb remained with its mother.

Surgical procedure. Surgical preparation, catheter care, and antibiotic administration were performed as described previously (24). In brief, after induction of halothane anesthesia, we performed a thoracotomy through the 4th intercostal space and sutured a Goretex conduit (inner diameter $6 \mathrm{~mm}$; W. L. Gore and Associates, Inc., Flagstaff, AZ) between the descending aorta and the main pulmonary artery at the level of the fibrotic string of the ductus arteriosus. Precalibrated electromagnetic flow transducers (inner diameter 10-15 mm; Skalar Medical, Delft, The Netherlands) were placed around the ascending aorta just above the coronary arteries and around the pulmonary artery proximal to the conduit. Polyvinyl catheters were placed in the ascending aorta, pulmonary artery, right ventricle, left and right atrium, and coronary sinus. In the coronary sinus, which was canulated via the left azygos vein, blood predominantly from the left ventricular free wall drains (25). Finally, the chest wall was closed in layers, and the catheters and flow probe cables were led through a subdermal tunnel to a cloth pouch sewn to the left flank of the lamb. For the control lambs, surgical instrumentation was the same except for the conduit, the flow transducer around the pulmonary artery, and the right ventricular catheter.

Experimental protocol. On the day of study, $12 \pm 1 \mathrm{~d}$ after surgery, the lamb was weighed at $0730 \mathrm{~h}$ and brought to the experimental room, where it was allowed to stand. To prevent interference with FFA metabolism, the heparin fluid was carefully aspirated from the catheters. Measurements were started after a 2-3 h habituation period, but only when the lamb stood quietly. Throughout the experiment and the $2-3$ preceding $h$, the lamb was allowed no food (25). Systemic and pulmonary blood flows, as well as aortic, pulmonary arterial, and left and right atrial pressures, were measured every $5 \mathrm{~min}$ over a 30 -min period. At 15 and $30 \mathrm{~min}$, blood samples $(0.7 \mathrm{~mL})$ were withdrawn from the aortic and coronary sinus catheters with a dry, heparinized syringe. $\mathrm{O}_{2}$ saturation was determined in all samples; $\mathrm{Hb}$ concentration, $\mathrm{pH}, \mathrm{PCO}_{2}, \mathrm{PO}_{2}$, and plasma $\mathrm{HCO}_{3}{ }^{-}$concentration were determined only in the sample from the aorta. Aortic hematocrit was determined by the microcapillary method in duplicate. At $30 \mathrm{~min}$, blood samples $(9 \mathrm{~mL})$ were drawn from the aortic and coronary sinus catheters to determine the myocardial substrate concentrations in triplicate. One additional blood sample $(4 \mathrm{~mL})$ was drawn from the aortic catheter to determine catecholamine concentrations. Immediately after collecting these blood samples, we injected radioactive microspheres labeled with either ${ }^{141} \mathrm{Ce},{ }^{51} \mathrm{Cr},{ }^{103} \mathrm{Ru}$, or ${ }^{95} \mathrm{Nb}$ (NEN-Trac; Dupont Co., Biotechnology Systems, Wilmington, DE) into the left atrium while a reference sample was simultaneously drawn with a pump (Harvard Apparatus Co., Millis, MA) from the aortic catheter into a preweighed, heparinized syringe for $1.25 \mathrm{~min}$ at a rate of $6 \mathrm{~mL} / \mathrm{min}(26)$.

Two identical experiments were performed in each lamb with a 2-d interval. In two shunt lambs, no second experiment could be performed because of obliteration of the coronary sinus catheter.

Measurements and calculations. The precalibrated electromagnetic flow transducers were connected to Skalar MDL 400 flow meters. Systemic blood flow of the shunt lambs was obtained from the pulmonary arterial flow transducer, which is situated proximal to the anastomosis of the shunt and the pulmonary artery and thus measures systemic venous return (see Fig. 1 from Ref. 3). Pulmonary blood flow of the shunt lambs was obtained from the aortic flow transducer, which is situated proximal to the anastomosis of the shunt and the aorta and thus measures pulmonary venous return. Systemic blood flow of the control lambs was obtained from the aortic flow transducer. The position of the aortic flow transducer in both groups was distal to the origin of the coronary arteries. To obtain total left ventricular output, the flow signal was later modified by adding coronary blood flow obtained with the microspheres (27.). Heart rate was obtained from the blood flow signal. Aortic and left atrial pressures were measured with Gould P23 ID pressure transducers (Spectramed Inc., Oxnard, CA) that were referenced to atmospheric pressure with zero obtained with the pressure transducer at right atrial level. All variables were recorded on an Elema Mingograf 800 ink-jet recorder (Siemens-Elema AB, Solna, Sweden). $\mathrm{O}_{2}$ saturation was determined in duplicate with an OSM2 hemoxymeter (Radiometer, Copenhagen, Denmark). pH, $\mathrm{PCO}_{2}$, $\mathrm{PO}_{2}$, and plasma $\mathrm{HCO}_{3}{ }^{-}$concentrations were determined with an ABL-2 blood gas analyzer (Radiometer). $\mathrm{Hb}$ concentration was determined with the methemoglobincyanide method (28). Left to right shunt flow was obtained by subtracting systemic from pulmonary blood flow. Left to right shunt fraction was calculated by dividing left to right shunt flow by pulmonary blood flow. Blood $\mathrm{O}_{2}$ concentration was calculated as the product of $\mathrm{O}_{2}$ saturation, $\mathrm{Hb}$ concentration, and an $\mathrm{Hb}$ binding capacity of $1.36 \mathrm{~mL} \mathrm{O}_{2} / \mathrm{g} \mathrm{Hb}(29)$.

Blood flow to the myocardium was determined with two of the four radionuclide-labeled $15-\mu \mathrm{m}$ microspheres injected in random order. After the second experiment, the lamb was killed with an overdose of i.v. pentobarbital. Then the heart, cerebral hemispheres, and kidneys were removed and weighed. The heart was cleared of its pericardium, great vessels, chordae, and epicardial fat. The left ventricular free wall was separated from the rest of the heart and both were weighed with an accuracy of 1 $\mathrm{mg}$. Radioactivity in the left ventricular free wall, the rest of the myocardium, hemispheres, kidneys, and reference samples was determined in a Beckman 9000 gamma counter (Beckman Instruments, Fullerton, CA). Organ blood flows were calculated from the radioactivity counts in the tissue samples and arterial reference samples with the aid of a special computer program (28). Blood flows were expressed in $\mathrm{mL} \cdot \mathrm{min}^{-1} \cdot 100 \mathrm{~g}^{-1}$ wet weight. Adequate mixing of the microspheres in each lamb was achieved by ascertaining that blood flow per $100 \mathrm{~g}$ of tissue to the two cerebral hemispheres, as well as to the two kidneys, did not differ by more than $10 \%$ (26).

Concentrations of glucose, pyruvate, lactate, $\beta-\mathrm{OH}$-butyrate, and acetoacetate were determined in triplicate in whole blood by enzymatic methods (30). Immediately after sample collection, the blood $(4.5 \mathrm{~mL})$ was transferred to a tube containing a dash of $\mathrm{NaF}$ and carefully mixed to prevent glycolysis. Then the blood was deproteinized with perchloric acid. After subsequent neutralization to $\mathrm{pH} 7$ with $\mathrm{KOH}$ and morpholinopropansulfonic acid solution, the mixture was centrifuged and the supernatant removed to determine the substrate concentrations (30).

Concentrations of FFA, total glycerol, and free glycerol were determined in triplicate in plasma. Immediately after sample collection, the blood $(4.5 \mathrm{~mL})$ was transferred to a chilled tube and centrifuged. The plasma was removed and stored without delay at $-70^{\circ} \mathrm{C}$, pending determination of the substrate concentrations. FFA concentration was determined enzymatically with a commercial kit (NEFAC; Wako Chemicals GmbH, Neuss, Germany) (31). Total glycerol concentration was determined similarly (Test-Combination Triglyceride; Boehringer Mannheim GmbH, Mannheim, Germany). Free glycerol was also determined enzymatically (30). Plasma concentrations were converted to blood concentrations through multiplication with the following factor: $[100-$ hematocrit $(\%)] / 100$. The triglyceride kit measures total glycerol concentration after hydrolysis of triglycerides. To obtain the triglyceride concentration, we subtracted free glycerol from total glycerol concentration.

Because coronary sinus blood consists predominantly of venous blood from the left ventricular free wall, we calculated myocardial $\mathrm{O}_{2}$ consumption of the left ventricular free wall as the product of aortocoronary sinus $\mathrm{O}_{2}$ concentration difference and blood flow to the left ventricular free wall (25) obtained with the radioactive microspheres. Similarly, we calculated myocardial substrate uptake as the product of aortocoronary sinus substrate concentration difference and blood flow to the left ventricular free wall. Substrate extraction ratio was calculated by 
dividing aortocoronary sinus difference by arterial substrate concentration.

To assess the relative importance of each substrate for myocardial oxidative metabolism, we calculated the OER $(10,17)$. It was calculated by assuming that during a steady state all of the substrate taken up by the myocardium is combusted, using the formula OER $=\left(\mathrm{ACS}_{\text {substrate }} \times \mathrm{N}\right) /\left(\mathrm{ACS}_{\text {oxygen }}\right)$, in which $\mathrm{ACS}$ is the aortocoronary sinus concentration difference and $\mathrm{N}$ represents the number of mol of oxygen required to completely combust $1 \mathrm{~mol}$ of substrate (25). $\mathrm{N}_{\text {glucose }}=6, \mathrm{~N}_{\text {pyruvate }}=2.5$, $\mathrm{N}_{\text {lactate }}=3, \mathrm{~N}_{\beta \text {-OH-butyrate }}=4.5, \mathrm{~N}_{\text {acetoacetate }}=4, \mathrm{~N}_{\mathrm{FFA}}=25$, and $\mathrm{N}_{\text {triglycerides }}=75(10,17) . \mathrm{N}$ is obtained from the stoichiometric relationship between oxygen and the respective substrate when expressed in equivalent molar concentrations.

Plasma noradrenaline and adrenaline concentrations were determined by HPLC with electrochemical detection (32). After sample collection, the blood was centrifuged in a cooled $\left(4^{\circ} \mathrm{C}\right)$ centrifuge. The thrombocyte-poor plasma was fortified with the antioxidant glutathion and stored at $-20^{\circ} \mathrm{C}$ pending determination.

Statistical analysis. Data are expressed as means \pm SEM. The differences between shunt and control lambs were evaluated with the Mann-Whitney test (33). Correlation coefficients and regression equations were calculated and are reported according to standard techniques $(33,34) . p \leq 0.05$ was considered significant.

\section{RESULTS}

There were no substantial differences in weight $(12.7 \pm 0.6$ versus $12.7 \pm 0.8 \mathrm{~kg})$ or age $(47 \pm 1$ versus $50 \pm 1 \mathrm{~d}, p<0.05)$ between shunt and control lambs. The left to right shunt led to significant hemodynamic differences between shunt and control lambs at rest (Table 1), differences that were similar to those reported previously from our laboratory $(3,24)$. Aortic systolic pressure in the present study was not significantly lower than in control lambs $(p=0.07)$, unlike mean aortic pressure $(65 \pm 1$ versus $71 \pm 2 \mathrm{mmHg}, p<0.01)$. Left ventricular mass of the

Table 1. Data for shunt and control lambs*

\begin{tabular}{|c|c|c|}
\hline & Shunt & Control \\
\hline \multicolumn{3}{|l|}{ Blood flow $\left(\mathrm{mL} \cdot \mathrm{min}^{-1} \cdot \mathrm{kg}^{-1}\right)$} \\
\hline Systemic & $121 \pm 4$ & $120 \pm 4$ \\
\hline Pulmonary & $297 \pm 12$ & $120 \pm 4 \dagger$ \\
\hline Heart rate (beats/min) & $164 \pm 5$ & $108 \pm 5 \dagger$ \\
\hline \multicolumn{3}{|l|}{ Pressure $(\mathrm{mm} \mathrm{Hg})$} \\
\hline Systolic aortic & $83 \pm 2$ & $88 \pm 2$ \\
\hline Left atrial & $15 \pm 1$ & $4 \pm 1 \dagger$ \\
\hline $\begin{array}{l}\text { L. ventricular stroke volume } \\
\qquad(\mathrm{mL} / \mathrm{kg})\end{array}$ & $1.83 \pm 0.06$ & $1.15 \pm 0.06 \dagger$ \\
\hline $\mathrm{Hb}(\mathrm{g} / \mathrm{L})$ & $93 \pm 1$ & $101 \pm 3 \dagger$ \\
\hline \multicolumn{3}{|l|}{$\mathrm{O}_{2}$ saturation $(\%)$} \\
\hline Aortic & $89 \pm 1$ & $92 \pm 0 \dagger$ \\
\hline Coronary sinus & $28 \pm 3$ & $24 \pm 3$ \\
\hline $\begin{array}{l}\text { Myocardial blood flow in left } \\
\text { ventricular free wall (mL. } \\
\left.\min ^{-1} \cdot 100 \mathrm{~g}^{-1}\right)\end{array}$ & $243 \pm 15$ & $129 \pm 9 \dagger$ \\
\hline Arterial pH & $7.41 \pm 0.01$ & $7.44 \pm 0.01$ \\
\hline Arterial $\mathrm{PCO}_{2}(\mathrm{~mm} \mathrm{Hg}) \ddagger$ & $41 \pm 1$ & $38 \pm 1 \dagger$ \\
\hline Arterial $\mathrm{PO}_{2}(\mathrm{~mm} \mathrm{Hg}) \ddagger$ & $102 \pm 2$ & $108 \pm 2$ \\
\hline Arterial $\mathrm{HCO}_{3}^{-}(\mathrm{mmol} / \mathrm{L})$ & $24.7 \pm 0.6$ & $24.3 \pm 0.6$ \\
\hline Arterial noradrenaline $(\mathrm{nmol} / \mathrm{L}) \S$ & $16 \pm 4$ & $8 \pm 2$ \\
\hline Arterial adrenaline $(\mathrm{nmol} / \mathrm{L}) \S$ & $2.1 \pm 0.5$ & $1.2 \pm 0.4$ \\
\hline
\end{tabular}

*Values are means \pm SEM; $n=22$ measurements in 12 shunt lambs and $n=20$ measurements in 10 control lambs. L. ventricular, left ventricular.

$\dagger p<0.05$, shunt $v s$ control.

$¥$ Conversion factor $\mathrm{mm} \mathrm{Hg}$ to $\mathrm{kPa}: \times 0.1333$.

$\S$ Conversion factor $\mathrm{nmol} / \mathrm{L}$ to $\mathrm{ng} / \mathrm{L}: \times 168$ and $\times 182$, for noradrenaline and adrenaline, respectively. shunt lambs was higher than that of the control lambs $(29 \pm 2$ versus $24 \pm 2 \mathrm{~g}, p<0.05$ ). Plasma noradrenaline and adrenaline concentrations were higher in shunt than in control lambs, but these differences did not reach statistical significance $(p=0.08$ and 0.07 , respectively). The power for the latter two tests, however, was low: 0.36 and 0.28 , respectively (33).

Arterial oxygen concentration was lower in shunt than in control lambs (Fig. 1) due to the lower $\mathrm{Hb}$ concentration and oxygen saturation (Table 1). Myocardial oxygen extraction ratio did not differ between the two groups, so the arteriovenous oxygen concentration difference across the myocardium was lower than in control lambs. However, left ventricular oxygen uptake in the shunt lambs was significantly higher than in control lambs as a consequence of the considerably higher myocardial blood flow. The increased myocardial oxygen consumption must be mainly due to the increase in heart rate, inasmuch as there was no difference in oxygen uptake per beat $(5.2 \pm 0.5$ versus $5.1 \pm 0.6 \mu \mathrm{mol} \mathrm{O} 2 \cdot$ beat $\left.^{-1} \cdot 100 \mathrm{~g}^{-1}\right)$. The effects of increased left ventricular stroke volume and end-diastolic pressure on external work and wall stress are counteracted by myocardial hypertrophy and decreased aortic pressure, resulting in a normalized myocardial $\mathrm{O}_{2}$ consumption per $100 \mathrm{~g}$ per beat (28).

Arterial substrate concentrations were not significantly different between the two groups (Fig. 1). Arteriovenous lactate concentration difference was higher in shunt than in control lambs. As a consequence, myocardial lactate extraction ratio was also higher in shunt than in control lambs $(8 \pm 3 \%$ versus $1 \pm 2 \% ; p$ $<0.05$ ). As for the other substrates, there were no significant differences between the two groups in arteriovenous concentration differences across the myocardium. Myocardial uptake of lactate was substantially higher in shunt than in control lambs due to the increased arteriovenous difference and the 2-fold increase in myocardial blood flow. Unlike oxygen uptake, myocardial lactate uptake increased more than heart rate so that lactate uptake per beat was still higher in shunt than in control lambs $\left(107 \pm 33\right.$ versus $16 \pm 25 \mathrm{nmol} \cdot$ beat $\left.^{-1} \cdot 100 \mathrm{~g}^{-1}, p<0.05\right)$. Inasmuch as the arteriovenous difference across the myocardium for the other substrates was similar in the two groups, their myocardial uptake paralleled the increase in myocardial blood flow in the shunt lambs, as was the case for myocardial oxygen consumption. The increased uptake of several substrates did not, however, reach statistical significance, a result for which we hold the spread of the values responsible. The variable nature of myocardial metabolism ["the heart is a scavenger" (17)] contributes to this spread because it varies according to arterial substrate concentrations and the between-substrate concentration relationships $(4,5)$.

Because myocardial lactate uptake in the shunt lambs was substantially more increased than oxygen uptake, the OER for lactate was considerably higher in shunt than in control lambs (Fig. 2). OER for total fatty acids (sum of FFA and those fatty acids derived from triglycerides) amounted to approximately 0.5 and that for ketone bodies amounted to 0.2 , in shunt as well as in control lambs. OER for glucose was 0.10 in shunt and 0.05 in control lambs. The sum of the OER of the different substrates did not add up to 1 . For both groups it was not significantly different from 1 , yet it could clearly be distinguished from 0 (shunt, $p<0.001$; control, $p<0.01$ ).

There was a significant correlation between arterial $\beta-\mathrm{OH}-$ butyrate concentrations and arteriovenous differences $(r=0.67$, $p<0.0001)$. An even higher correlation was found between arterial concentrations and OER of $\beta$-OH-butyrate $(r=0.82 ; p$ $<0.0001$ ) (Fig. 3). Subdivision into shunt and control lambs showed significant correlations in both groups.

\section{DISCUSSION}

The overall pattern of myocardial substrate uptake in shunt lambs is not substantially different from that in control lambs. Myocardial uptake of the substrates in the shunt lambs parallels 

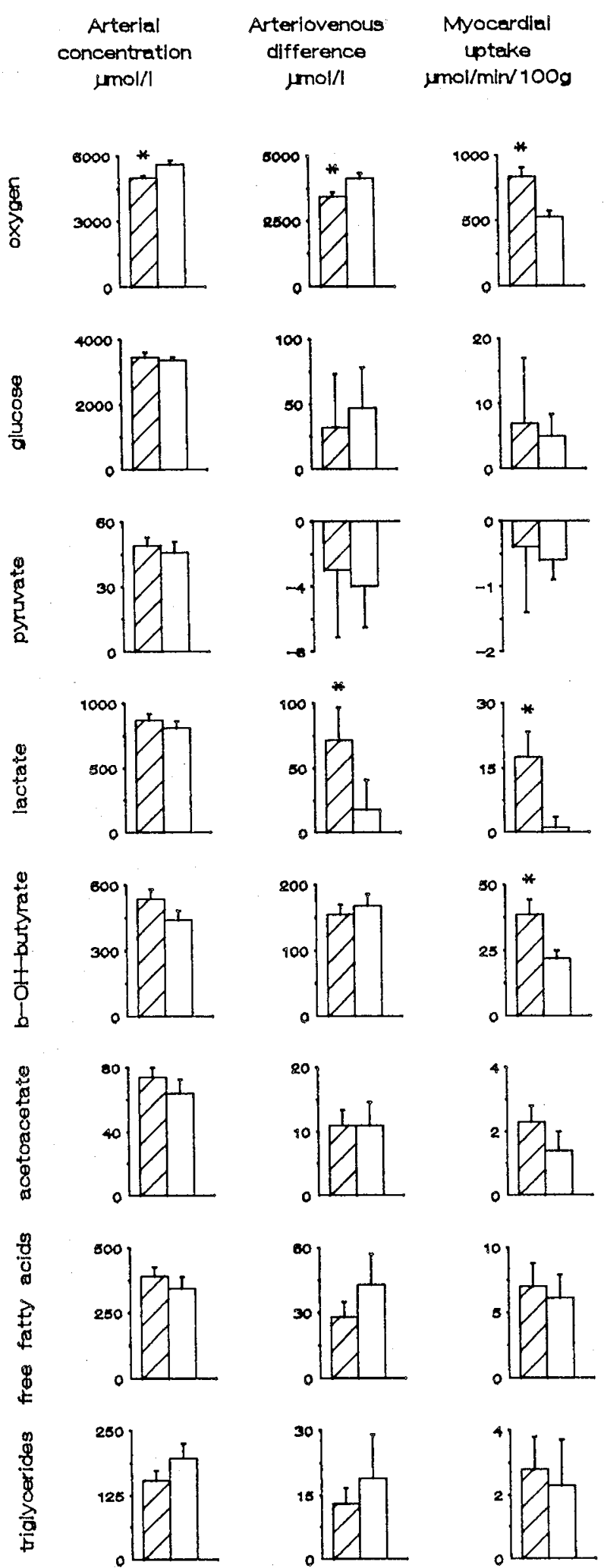

Fig. 1. Arterial $\mathrm{O}_{2}$ and substrate concentrations and arteriovenous difference across and uptake by the left ventricular free wall of shunt (hatched bars, $n=22$ measurements in 12 lambs) and control lambs (open bars, $n=20$ measurements in 10 lambs) (means \pm SEM). Asterisks indicate a significant difference between shunt and control lambs.

the increased myocardial blood flow. The only exception, however, is lactate, the uptake of which is 15 times higher than in control lambs. This is the result not only of an increased myocardial blood flow but also of an additionally increased lactate

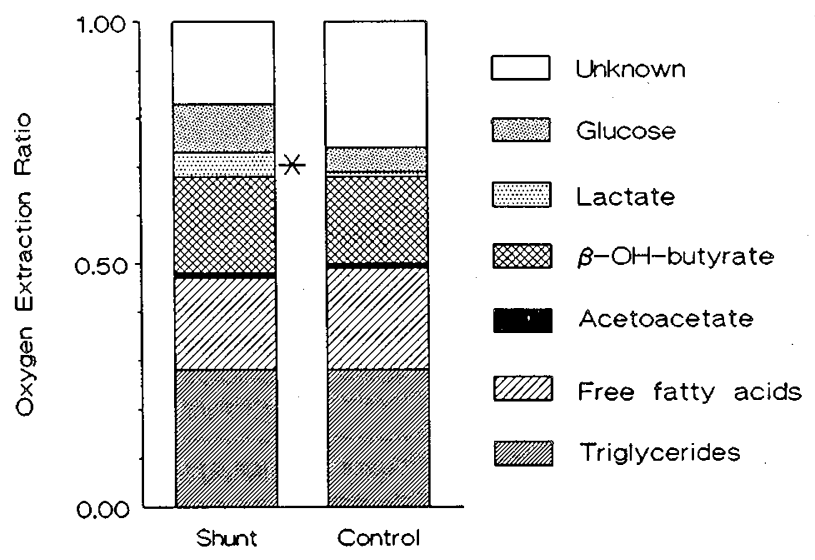

Fig. 2. OER of the various myocardial substrates for shunt and control lambs. Asterisk indicates a significant difference between shunt and control lambs.

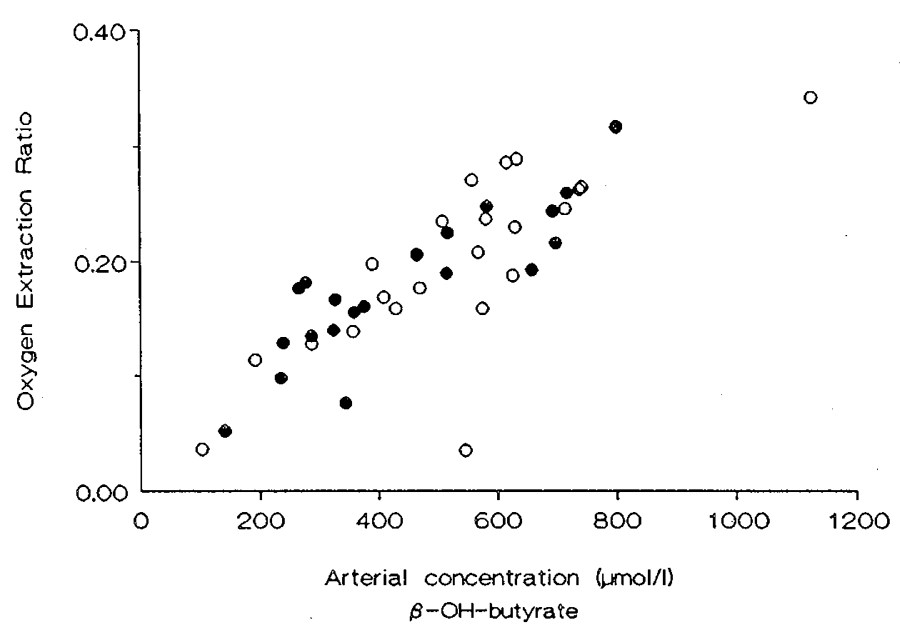

Fig. 3. Arterial $\beta$-OH-butyrate concentration versus $\beta$-OH-butyrate OER in shunt (open circles) and control lambs (closed circles). There was a significant correlation $[r=0.82, p<0.0001, n=42, y=0.28$. $10^{-3}\left( \pm 0.32 \cdot 10^{-4}, \mathrm{SEM}\right) \cdot x+0.050( \pm 0.017)$, residual variance 0.0018$]$. There was also a significant correlation between arterial $\beta-\mathrm{OH}$-butyrate concentration and arteriovenous $\beta$-OH-butyrate difference $[r=0.67, p$ $<0.0001, n=42, y=0.24( \pm 0.04) \cdot x+41( \pm 22) \mu \mathrm{mol} / \mathrm{L}$, residual variance 3154].

extraction by the myocardium.

An increased myocardial lactate utilization has been previously demonstrated at rest $(35,36)$, during exercise $(4,10-12,17,35$, $37-39)$, or during septic shock (40). However, a common feature in all of these studies is an increased arterial lactate concentration. This enhances myocardial lactate uptake because arterial substrate concentration is a major determinant of myocardial substrate selection $(4,5,16,17)$.

The present data now demonstrate an increased lactate uptake by the myocardium in the shunt lambs, whereas arterial lactate concentration is equal to that in control lambs. This indicates that there is an intrinsic difference between the myocardium of shunt and control lambs. It is likely that the increased arteriovenous difference for lactate across the myocardium of the shunt lambs is due to an increase in enzyme activity leading to increased myocardial lactate extraction and/or more efficient use of intracellular lactate $(11,41)$. Probably, PDH or LDH-H activity, or both, are increased, inasmuch as these enzymes control the pathway between lactate uptake and acetyl-CoA formation $(5,16)$.

PDH activity increases by catecholamine stimulation $(42,43)$ and increased myocardial work load. LDH can adapt itself to changing circumstances by changing its isoenzyme profile (44- 
46). The $\mathrm{H}$-subunit activity distribution in the heart parallels the amount of work performed by the different regions of the heart. Its activity is for instance higher in left than in right ventricular myocardium (47). It is therefore conceivable that the myocardium in shunt lambs adapts itself to the chronically increased work load by changing its LDH isoenzyme profile toward increased H-subunit activity. In combination with increased PDH activity, this could lead to increased lactate utilization by the myocardium. This is in agreement with studies in dogs and humans that have shown that the enhancing effect of acute (37) as well as chronically (39) increased myocardial work load on lactate uptake is in addition to the effect of increased arterial lactate concentration. It also fits the finding of a decreased $\mathrm{Km}$ for the conversion of lactate into pyruvate in rat heart homogenates after $10 \mathrm{wk}$ of treadmill training, suggesting that a heart with a chronically increased work load is more capable of utilizing lactate as a fuel for energy metabolism $(39,48)$.

The contribution of lactate to myocardial oxidative metabolism is small, and in absolute values the difference between shunt and control lambs is small. However, despite the large spread in the values, which is inherent in myocardial metabolism, the difference between the two groups emerges as a significant one. On the clinical significance of increased lactate, we can only speculate. It could be a mere accompanying feature of increased work load, as discussed in the paragraph above. Or it could reflect adaptive changes in PDH or LDH isoenzymes that accompany various states of myocardial (de)compensation $(45,46)$. Furthermore, myocardial hypertrophy has been demonstrated to be accompanied by abnormal gene expression, leading to synthesis of fetal myocardial protein isoforms (44). The fetal lamb myocardium predominantly uses lactate as a fuel (25). Our findings of increased myocardial lactate uptake in the hypertrophied heart could reflect the presence of fetal myocardial proteins in the shunt lambs.

Increased work load and catecholamines may enhance fatty acid metabolism $(5,15)$. In the shunt lambs, catecholamine concentration did not quite reach statistical significance $(0.05<$ $p<0.10$ ). The power of the test, however, was low, so that the chance of statistically missing a difference was large. The lack of enhancement of fatty acid uptake may be due to the period of time that the myocardium was exposed to the increased work load. Studies on the effects of increased work load and catecholamines on myocardial metabolism have often dealt with acute effects. Presumably, the myocardium of the shunt lambs adapted during the 2 wk that the shunt was present. Normalization of myocardial metabolism with time during a constant stress after initial change has been demonstrated before: during a 50- or 120min treadmill run, myocardial lactate and fatty acid uptake acutely changed but tended to return to resting values during the run $(11,12)$.

It has been reported that in newborn lambs up to 2 wk of age, as well as in adult sheep, glucose and lactate constitute only a minor fraction of total myocardial energy producing substrates (49). Our data confirm this for 7-wk-old lambs. Data with regard to the other substrates that supply myocardial energy in newborns have been lacking up to now (50). Of special interest is the contribution of fatty acids because they do not contribute to myocardial metabolism in the fetal lamb (25), in contrast to the situation in the adult (5). Our data reveal that by $7 \mathrm{wk}$ after birth fatty acids constitute the major substrate for myocardial energy metabolism, as is the case for the adult human heart $(5,16,17$, $19,50)$. In addition, ketone bodies form an important source for energy metabolism, accounting for approximately $20 \%$ of oxidative metabolism in shunt as well as in control lambs. This is probably due to a higher ketone body concentration in the blood of lambs than in that of human children $(\sim 0.2 \mathrm{mmol} / \mathrm{L}),(4,17$ 51) resulting from the difference in gastrointestinal digestion between the human and the ovine species. The fermentation of hay in the stomachs and intestines of sheep produces short-chain fatty acids that are converted to ketone bodies in the liver (51,
52). The presence of hay in the stomachs of all lambs was confirmed at autopsy.

The cumulative OER did not add up to 1. The outcome, however, was not statistically different from 1 . The cumulative OER does not necessarily have to equal 1.0 because OER yields approximate values; there is a potential source of error because OER is calculated from four measurements: arterial and coronary sinus concentration of $\mathrm{O}_{2}$ and substrate (17). Also, it is calculated under the assumption that all substrates taken up by the myocardium undergo complete oxidation in the steady state. Recent isotope-labeled substrate studies have shown that this is not exactly true $(41,53,54)$. OER overestimates the glucose utilization because $\sim 13 \%$ is released as lactate (41), whereas lactate and fatty acid utilizations are underestimated. Pyruvate utilization may be overestimated because pyruvate is converted to alanine in small amounts (5). Glucose and fatty acids extracted by the myocardium also enter slow turnover pools, probably glycogen and triglyceride pools $(41,53)$. In a steady state, we assume that equal amounts are added to and released from these endogenous stores. Despite the inaccuracy, OER is a practical means to obtain an impression of substrate utilization.

We speculate that part of the "missing" myocardial substrates in both groups are short-chain fatty acids, predominantly acetate, which are released by carbohydrate fermentation in the stomach (51) and which are not measured by the FFA kit (31). Acetate is taken up and oxidized more readily in the tricarboxylic acid cycle without complex metabolic pathways than, for instance, fatty acids $(17,19,55)$. Furthermore, the deficit could reflect substrate use from myocardial glycogen or triglyceride stores. We do not think, however, that this is very likely because the lambs are assumed to be in a steady state (10). The role of endogenous myocardial stores of substrates has not been elucidated. They form a buffer for substrates extracted from the blood and normally do not constitute an important energy source, except in emergencies such as the sudden onset of hard work or of ischemia $(17,56)$. Moreover, the combined myocardial glycogen and triglyceride stores would be depleted within several hours if $20 \%$ of substrates would be retrieved from endogenous stores (56).

In conclusion, the left to right shunt is not accompanied by a substantial change in myocardial substrate uptake pattern. However, myocardial lactate uptake is significantly increased. Because the arterial lactate concentration was not higher in shunt than in control lambs, we hypothesize that the increased myocardial lactate extraction is due to an increased PDH or LDH-H activity, or both.

Acknowledgments. The authors thank Ineke Top-Dalebout and Marchien Velvis (Central Laboratory for Clinical Chemistry, University Hospital, Groningen) for determinations of the FFA and catecholamine concentrations and R. Berger (former head of the research laboratory, Department of Pediatrics, University Hospital, Groningen) for his inspiring remarks.

\section{REFERENCES}

1. Gibbs CL 1978 Cardiac energetics. Physiol Rev 58:174-254

2. Suga H 1990 Ventricular energetics. Physiol Rey 70:247-277

3. Toorop GP, Hardjowijono R, Dalinghaus M, Gerding AM, Koers JH, Zijlstra WG, Kuipers JRG 1987 Myocardial blood flow and $\mathrm{VO}_{2}$ in conscious lambs with an aortopulmonary shunt. Am J Physiol 252:H681-H686

4. Taegtmeyer H 1988 Principles of fuel metabolism in heart muscle. In: De Jong JW (ed) Myocardial Energy Metabolism. Martinus Nijhoff Publishers, Dordrecht, The Netherlands, pp 17-34

5. Randle PJ, Tubbs PK 1979 Carbohydrate and fatty acid metabolism. In: Shepherd JT, Abboud FM (eds) Handbook of Physiology, Section 2: The Cardiovascular System, Vol I, The Heart. American Physiological Society, Bethesda, MD, pp 805-844

6. Kagaya Y, Kanno Y, Takeyama D, Ishide N, Maruyama Y, Takahashi T, Ido T, Takishima T 1990 Effects of long-term pressure overload on regional myocardial glucose and free fatty acid uptake in rats. Circulation 81:13531361

7. Ribeilima J, Wendt VE, Ramos H 1964 The effects of norepinephrine on the hemodynamics and myocardial metabolism of normal human subjects. Am Heart J 67:672-678 
8. Tanaka T, Morita H, Koide H, Kawamura K, Takatsu T 1985 Biochemical and morphological study of cardiac hypertrophy. Effects of thyroxine on enzyme activities in the rat myocardium. Basic Res Cardiol 80:165-174

9. Fintel M, Burns AH 1982 Effects of thyroxine treatment on exogenous myocardial lactate oxidation. Am J Physiol 243:H722-H728

10. Keul J, Doll E, Steim H, Fleer U, Reindell H 1965 Über den Stoffwechsel des menslichen Herzens. III. Der oxidative Stoffwechsel des menslichen Herzens unter verschiedenen Arbeitsbedingungen. Pflugers Arch 282:43-53

11. Gertz EW, Wisnesky JA, Stanley WC, Neese RA 1988 Myocardial substrate utilization during exercise in humans. Dual carbon labeled carbohydrate isotope experiments. J Clin Invest 82:2017-2025

12. Kaijser L, Lassers BW, Wahlqvist ML, Carlson LA 1972 Myocardial lipid and carbohydrate metabolism in fasting men during prolonged exercise. $\mathrm{J}$ Appl Physiol 32:847-858

13. Fujisawa A, Sasayama S, Takahashi M, Nakamura M, Ohyagi A, Lee J-D, Yui Y, Kawai C 1984 Enhancement of left ventricular contractility after opening of an arteriovenous fistula in dogs. Cardiovasc Res 18:51-59

14. Mayer SE 1974 Effects of catecholamines on cardiac metabolism. Circ Res 34, 35(suppl II): 129-135

15. Rovetto MJ 1981 Myocardial metabolism. In: Wilkerson RD (ed) Cardiac Pharmacology. Academic Press, New York, pp 335-359

16. Neely JR, Morgan HE 1974 Relationship between carbohydrate and lipid metabolism and the energy balance of heart muscle. Annu Rev Physiol 36:413-459

17. Opie LH 1991 Fuels: carbohydrates and lipids. In: Opie LH (ed) The Heart. Physiology and Metabolism. Raven Press, New York, pp 208-247

18. Mjøs OD 1971 Effect of free fatty acids on myocardial function and oxygen consumption in intact dogs. J Clin Invest 50:1386-1389

19. Camici P, Ferrannini E, Opie LH 1989 Myocardial metabolism in ischemic heart disease: basic principles and application to imaging by positron emission tomography. Prog Cardiovasc Dis 32:217-238

20. Hütter JF, Piper HM, Spiekermann PG 1985 Effect of fatty acid oxidation on efficiency of energy production in rat heart. Am J Physiol 249:H723-H728

21. Lopaschuk GD, Spafford MA, Davies NJ, Wall SR 1990 Glucose and palmitate oxidation in isolated working rat hearts reperfused after a period of transient global ischemia. Circ Res 66:546-553

22. Snow TR 1978 Substrate effects on myocardial performance during normoxemia and hypoxia. Am J Physiol 235:H144-H149

23. Kahles H, Hellige G, Hunneman DH, Mezger VA, Bretschneider HJ 1982 Influence of myocardial substrate utilization on the oxygen consumption of the heart. Clin Cardiol 5:286-293

24. Gratama JWC, Meuzelaar JJ, Dalinghaus M, Koers JH, Werre AJ, Zijlstra WG, Kuipers JRG 1990 Maximal exercise capacity and oxygen consumption of lambs with an aortopulmonary left-to-right shunt. J Appl Physiol 69:14791485

25. Fisher DJ, Heymann MA, Rudolph AM 1980 Myocardial oxygen and carbohydrate consumption in fetal lambs in utero and in adult sheep. Am J Physiol 238:H399-H405

26. Heymann MA, Payne BD, Hoffman JIE, Rudolph AM 1977 Blood flow measurement with radionuclide-labeled particles. Prog Cardiovasc Dis 20:55-79

27. Kuipers JRG, Sidi D, Heymann MA, Rudolph AM 1982 Comparison of methods of measuring cardiac output in newborn lambs. Pediatr Res 16:594598

28. Gratama JWC, Meuzelaar JJ, Dalinghaus M, Koers JH, Gerding AM, Monchen MTM, Nijenhuis FCAMt, Zijlstra WG, Kuipers JRG 1992 Myocardial blood flow and $\mathrm{VO}_{2}$ in lambs with an aortopulmonary shunt during strenuous exercise. Am J Physiol (in press)

29. Lister G, Walter TK, Versmold HT, Dallman PR, Rudolph AM 1979 Oxygen delivery in lambs: cardiovascular and hematologic development. Am J Physiol 237:H668-H675

30. Bergmeyer HU 1970 Methoden der Enzymatische Analyse. Verlag Chemie, Weinheim, Germany

31. Demacker PNM, Hijmans AGM, Jansen AP 1982 Enzymic and chemicalextraction determinations of free fatty acids in serum compared. Clin Chem 28:1765-1768

32. Smedes F, Kraak JC, Poppe H 1982 Simple and fast solvent extraction system for selective and quantitative isolation of adrenaline, noradrenaline, and dopamine from plasma and urine. J Chromatogr 231:25-38

33. Zar JH 1984 Biostatistical Analysis. Prentice Hall Inc, Englewood Cliffs, NJ

34. Godfrey K 1986 Simple linear regression in medical research. In: Bailar III JC, Mosteller F (eds) Medical Uses of Statistics. New England Journal of Medicine Books, Waltham, MA, pp 170-204

35. Drake AJ, Haines JR, Noble MIM 1980 Preferential uptake of lactate by the normal myocardium in dogs. Cardiovasc Res 14:65-72

36. Drake-Holland AJ 1983 Substrate utilization. In: Drake-Holland AJ, Noble MIM (eds) Cardiac Metabolism. John Wiley \& Sons, Chichester, England, pp 195-214

37. Hirche H, Lochner W 1961 Über den Stoffwechsel des Herzens bei vermehrtem Milchsäureangebot. Verh Dtsch Ges Kreislaufforsch 27:207-212

38. Keul J, Krauss H, Overbeck W, Doll E, Fleer U 1964 Über den Stoffwechsel des keine Druck- und Volumenarbeit leistenden menslichen Herzens. Klin Wochenschr 42:890-899

39. Keul J, Doll E, Steim H, Homberger H, Kern H, Reindell H 1966 Über den Stoffwechsel des Herzens bei Hochleistungssportlern. I. Der Substratversorgung des trainierten Herzens in Ruhe, während und nach korperliche Arbeit. Z Kreislaufforsch 55:190-215

40. Dhainaut JF, Huyghebaert MF, Monsallier JF, Lefevre G, Dall'Ava-Santucci J, Brunet F, Villemant D, Carli A, Raichvarg D 1987 Coronary hemodynamics and myocardial metabolism of lactate, free fatty acids, glucose and ketones in patients with septic shock. Circulation 75:533-541

41. Wisneski JA, Gertz EW, Neese RA, Gruenke LD, Morris DL, Craig JC 1985 Metabolic fate of extracted glucose in normal human myocardium. $\mathrm{J}$ Clin Invest 76:1819-1827

42. McCormack JG, Denton RM 1981 The activation of pyruvate dehydrogenase in the perfused rat heart by adrenaline and other inotropic agents. Biochem J 194:639-643

43. Bünger R, Permanetter B, Sommer O, Yaffe S 1982 Adaptive changes of pyruvate oxidation in perfused heart during adrenergic stimulation. Am $\mathrm{J}$ Physiol 242:H30-H36

44. Katz AM 1990 Cardiomyopathy of overload. N Engl J Med 322:100-110

45. Schultheiss H-P, Zäringer J, Scheidt WV, Ulrich G 1986 Myocardial lactate dehydrogenase isoenzyme distribution in chronic heart failure before and after treatment with enalapril. Circulation 74(suppl II):508(abstr)

46. Sylvén C, Jansson E, Szamosi A, Böök K 1989 Key enzymes of myocardial energy metabolism in papillary muscle of patients with mitral valve disease in relation to left ventricular function. Scand $\mathrm{J}$ Thorac Cardiovasc Surg 23:63-67

47. Sylvén LL, Sotonyi P, Somogyi E, Kaijser L, Jansson E 1989 Lactate dehydrogenase and its isoenzyme activities in different parts of the normal human heart. Cardiovasc Res 23:601-606

48. Ji LL, Stratman FW, Lardy HA 1986 Chronic exercise training alters kinetic properties of rat skeletal muscle and myocardial lactate dehydrogenase. FEBS Lett 208:297-300

49. Fisher DJ, Heymann MA, Rudolph AM 1981 Myocardial consumption of oxygen and carbohydrates in newborn sheep. Pediatr Res 15:843-846

50. Vick III GW, Fisher DJ 1990 Cardiac metabolism. In: Garson Jr A, Bricker JT, McNamara DG (eds) The Science and Practice of Pediatric Cardiology, Vol 1. Lea \& Febiger, Philadelphia, pp 191-201

51. Bergman EN 1990 Energy contributions of volatile fatty acids from the gastrointestinal tract in various species. Physiol Rev 70:567-590

52. Annison EF, Leng RA, Lindsay DB, White RR 1963 The metabolism of acetic acid, propionic acid, and butyric acid in sheep. Biochem $J$ 88:248-252

53. Wisneski JA, Gertz EW, Neese RA, Mayr M 1987 Myocardial metabolism of free fatty acids. Studies with ${ }^{14} \mathrm{C}$ labeled substrates in humans. $\mathrm{J}$ Clin Invest 79:359-366

54. Nosadini R, Avogaro A, Doria A, Fioretto P, Trevisan R, Morocutti A 1989 Ketone metabolism: a physiological and clinical overview. Diabetes Metab Rev 5:299-319

55. Brown M, Marshall DR, Sobel BE, Bergmann SR 1987 Delineation of myocardial oxygen utilization with carbon-11-labeled acetate. Circulation 76:687-696

56. Lehninger LA 1975 Organ interrelationships in the metabolism of mammals. In: Lehninger LA (ed) Biochemistry. Worth Publishers Inc, New York, pp $838-839$ 